\title{
Non-Uniform Magnetic Field Effects on Ferrofluids Film Boiling: A Numerical Study
}

\author{
Rasool Maroofiazar ${ }^{1, *}$ and Seyyede Fatemeh Haghgoo ${ }^{2}$ \\ ${ }^{1}$ Department of Mechanical Engineering, Faculty of Engineering, University of \\ Maragheh, Maragheh, Iran \\ ${ }^{2}$ Department of Mechanical Engineering, Faculty of Energy and Mechanical \\ Engineering, Shahid Beheshti University, Tehran, Iran \\ E-mail:maroofiazar@maragheh.ac.ir \\ *Corresponding Author
}

Received 19 March 2020; Accepted 19 March 2020;
Publication 11 May 2020

\begin{abstract}
In this paper the effect of magnetic field on film boiling of ferrofluids on a horizontal flat plate has been investigated. The obtained results indicate that adding nanoparticles into the base fluid changes vapor film characteristics mainly due to changes in thermophysical properties of the base fluid. Also, ferrofluids enhances film boiling heat transfer on horizontal plate specially at higher volume concentration of nanoparticles. Another important result of this study is the effect of non-uniform magnetic field on horizontal film boiling characteristics. Application of magnetic field changes vapor film behavior mostly at higher values of magnetic field intensity (400) and nanoparticles volume fraction (4 percent).
\end{abstract}

Keywords: Ferrofluid, film boiling, magnetic field, VOF model.

\section{Introduction}

If a surface heating the liquid is significantly hotter than the liquid then film boiling will occur, where a thin layer of vapor which has low thermal

European Journal of Computational Mechanics, Vol. 28_6, 635-666.

doi: 10.13052/ejcm2642-2085.2864

(C) 2020 River Publishers 
conductivity, insulates the surface. This condition of a vapor film insulating the surface from the liquid characterizes film boiling. Although film boiling is considered to be an inefficient mechanism of heat transfer but it occurs in many of practical engineering applications such as: quenching of metals, chilling of biological species, regenerative cooling of rockets, cooling down a cryogenic fuel tank, and sometimes film boiling can also happen in the nuclear reactor or in the cryomagnet [1].

Various studies have been made on film boiling in different conditions and geometries both experimentally and numerically such as: vertical surfaces [2], horizontal surfaces [3, 4], cylinders [5], spheres [6-10]. Most of the previous studies considered a pure fluid (such as water) as a working fluid. But as we know, a new type of fluids has been considered recently in many of studies and applications, named nanofluids.

Nanofluids are special type of fluids engineered by adding nano-sized particles in base fluids such as water and refrigerants. Magnetic fluids (ferrofluids) are special types of nanofluids which are synthesized by adding magnetic nanoparticles (e.g., $\mathrm{Fe}_{3} \mathrm{O}_{4}$ ) into the common base fluids. Hydrothermal behavior of a ferrofluid can be controlled by application of external magnetic fields and it is applicable in various fields such as electronic packing, mechanical engineering, thermal engineering, aerospace and bioengineering [11-14].

Film boiling of nanofluids and its applications has taken more attention in recent years. In these studies, the effect of adding of nanoparticles in the base fluid on the hydro-dynamical and thermal behavior of film boiling have been studied. Park et al. [15] performed quenching experiments on high temperature sphere in $\mathrm{Al}_{2} \mathrm{O}_{3}$ nanofluids and compared their results with the data of pure water film boiling. They concluded that adding nanoparticles into the base fluid enhances vaporization process during the film boiling.

Arai and Furuya [16] studied the effect of nanofluid on the film boiling behavior at vapor film collapse on a sphere. Their results indicate that heat transfer rate of $\mathrm{Al}_{2} \mathrm{O}_{3}$ nanofluid is almost the same or slightly lower than that of water.

Kim et al. [17] obtained quenching curve for small metallic spheres exposed to pure water and different water-based nanofluids. Similar quenching behavior was found in pure water and nanofluids. However, deposition of nanoparticles on the surface and related changes in surface roughness and wettability caused the quenching process to be accelerated.

Bolukbasi and Ciloglu [18] experimentally studied the effect of nanofluids on saturated pool film boiling on a vertical cylindrical rod. The obtained results showed that pool film boiling heat transfer in nanofluid was identical 
to that in pure fluid. Repetition tests were performed and the results indicated that film boiling region disappeared and critical heat flux increased due to the particle deposition and consequently changing the surface roughness of the rod. Another study with other types of nanofluids were performed with these authors [19] and almost the same results have been obtained.

Boiling heat transfer of nanofluids (water containing different sizes of carbon nanotubes) in quenching process was investigated experimentally [20]. The increases of the nucleation site density and surface roughness due to the presence of porous layers were identified as the primary cause for the modified boiling behaviors during quenching.

Malvandi et al. [21] theoretically investigated the impact of nanoparticle migration on the heat transfer enhancement at film boiling of nanofluids over a vertical cylinder. Their results indicated that nanoparticle migration considerably affects the flow fields and heat transfer rate. It was shown that the smaller nanoparticles are able to accumulate at the heated wall and enhance the heat transfer rate. For larger nanoparticles, however, nanoparticle depletion at the heated walls prevents considerable enhancement in the heat transfer rate.

Magnetic nanofluids can be exploited as a coolant (thermal management applications) and/or a heat transfer medium in energy conversion systems [22]. Although boiling flow and heat transfer of ferrofluids under application of magnetic fields have been paid more attention recently, but it is needed to further studies on the film boiling of this kind of fluids.

Khoshmehr et al. [23] experimentally investigated the effect of magnetic field on quenching of a cylinder in ferrofluids. Their obtained results depicted that with the implementation of magnetic field above the fluid pool, a secondary upward current was produced which caused an acceleration in release of the bubbles of steam. Also, the application of magnetic field caused considerable increase in film boiling heat flux.

Malvandi $[24,25]$ has studied film boiling of magnetic nanofluids over a vertical plate under influence of an external magnetic field. It has been illustrated in both studies that the heat transfer was improved when an external magnetic field exerted in the direction of the temperature gradient.

This literature review shows that a few studies have been made on the effect of magnetic field on film boiling characteristics of ferrofluids. Also, almost all of the previously mentioned works are experimental, and numerical studies are less. In addition, the most of the previously mentioned works, measured heat flux and temperature as important parameters and heat transfer coefficient and vapor film profile has been attracted less attention. 
Accordingly, in the present paper, film boiling of ferrofluids with two concentrations of nanoparticles has been considered on a horizontal flat plate. Also, for investigation of the effect of wall superheat on the film boiling characteristics, two value of plate superheats have been considered. Bubble's growth and detachment, and Nu number diagrams are illustrated as important parameters.

\section{Theoretical Formulation}

\subsection{Governing Equations}

VOF method is a free-surface modelling technique for tracking the interface of two or more immiscible fluids by solving a single set of momentum equations and tracking the volume fraction of each of the fluids throughout the domain.

\section{Continuity equation}

The tracking of the interface between the phases is accomplished by the solution of a continuity equation for the volume fraction of one (or more) of the phases.

$$
\frac{1}{\rho_{q}}\left[\frac{\partial}{\partial t}\left(\alpha_{q} \rho_{q}\right)+\nabla \cdot\left(\alpha_{q} \rho_{q} \overrightarrow{v_{q}}\right)=S_{\alpha_{q}}+\sum_{p=1}^{n}\left(\dot{m}_{p q}-\dot{m}_{q p}\right)\right]
$$

where $\dot{m}_{q p}$ is the mass transfer from phase $q$ to phase $p$ and $\dot{m}_{p q}$ is the mass transfer from phase $p$ to phase $q$. By default, the source term on the right-hand side of Equation (1), $S_{\alpha_{q}}$, is zero, but we can specify a constant or userdefined mass source for each phase. The second term in the above equation denotes the mass transfer effect at the interface and is non-zero only at the interface.

The volume fraction equation will not be solved for the primary phase; the primary-phase volume fraction will be computed based on the following constraint:

$$
\sum_{q=1}^{n} \alpha_{q}=1
$$

\section{Momentum equation}

A single momentum equation is solved throughout the domain, and the resulting velocity field is shared among the phases. The momentum equation 
for a cell is as follows:

$$
\rho\left(\frac{\partial \vec{V}}{\partial t}+\vec{V} \cdot \nabla \vec{V}\right)=-\nabla p+\nabla \cdot \mu\left[\nabla \vec{V}+(\nabla \vec{V})^{T}\right]+\rho \vec{g}
$$

which the second term in the right hand side demonstrates the rat of deformation. At the interface of liquid-vapor, the above equation is modified as follows:

$$
\rho\left(\frac{\partial \vec{V}}{\partial t}+\vec{V} \cdot \nabla \vec{V}\right)=-\nabla p+\nabla \cdot \mu\left[\nabla \vec{V}+(\nabla \vec{V})^{T}\right]+\rho \vec{g}+F_{s t}
$$

$F_{s t}$ is the interfacial volumetric surface tension force and can be written as $F_{s t}=F_{s a} \delta_{s}$. This force is equal to the sum of normal and tangential surface stresses:

$$
F_{s a}=f_{n}+f_{t}
$$

where $f_{n}=\sigma \kappa \vec{n}$ and $f_{t}=\partial \sigma / \partial x_{i}$ are normal and tangential stress in phases interface, respectively. The tangential stress can be neglected due to the very small changes of $\sigma$ with temperature and concentration, and consequently, the net stress at the interface will be $F_{s t}=\sigma \kappa \vec{n} \delta_{s}$.

\section{Energy equation}

The energy equation, also shared among the phases, is shown below:

$$
\rho c_{p}\left(\frac{\partial T}{\partial t}+\vec{V} \cdot \nabla T\right)=\nabla \cdot k(\nabla T)
$$

For saturated film boiling, the energy equation is solved only at the superheated vapor region and there is no need for solving energy equation at the interface. The VOF model treats energy, $E$, and temperature, $T$, as mass-averaged variables:

$$
E=\frac{\sum_{q=1}^{n} \alpha_{q} \rho_{q} E_{q}}{\sum_{q=1}^{n} \alpha_{q} \rho_{q}}
$$

where $E_{q}$ for each phase is based on the specific heat of that phase and the shared temperature.

\subsection{Studied Geometry and Boundary Conditions}

\subsubsection{Geometry}

Film boiling on a horizontal flat plate has been considered in this paper. The studied geometry and its boundary conditions has been illustrated in Figure 1. 


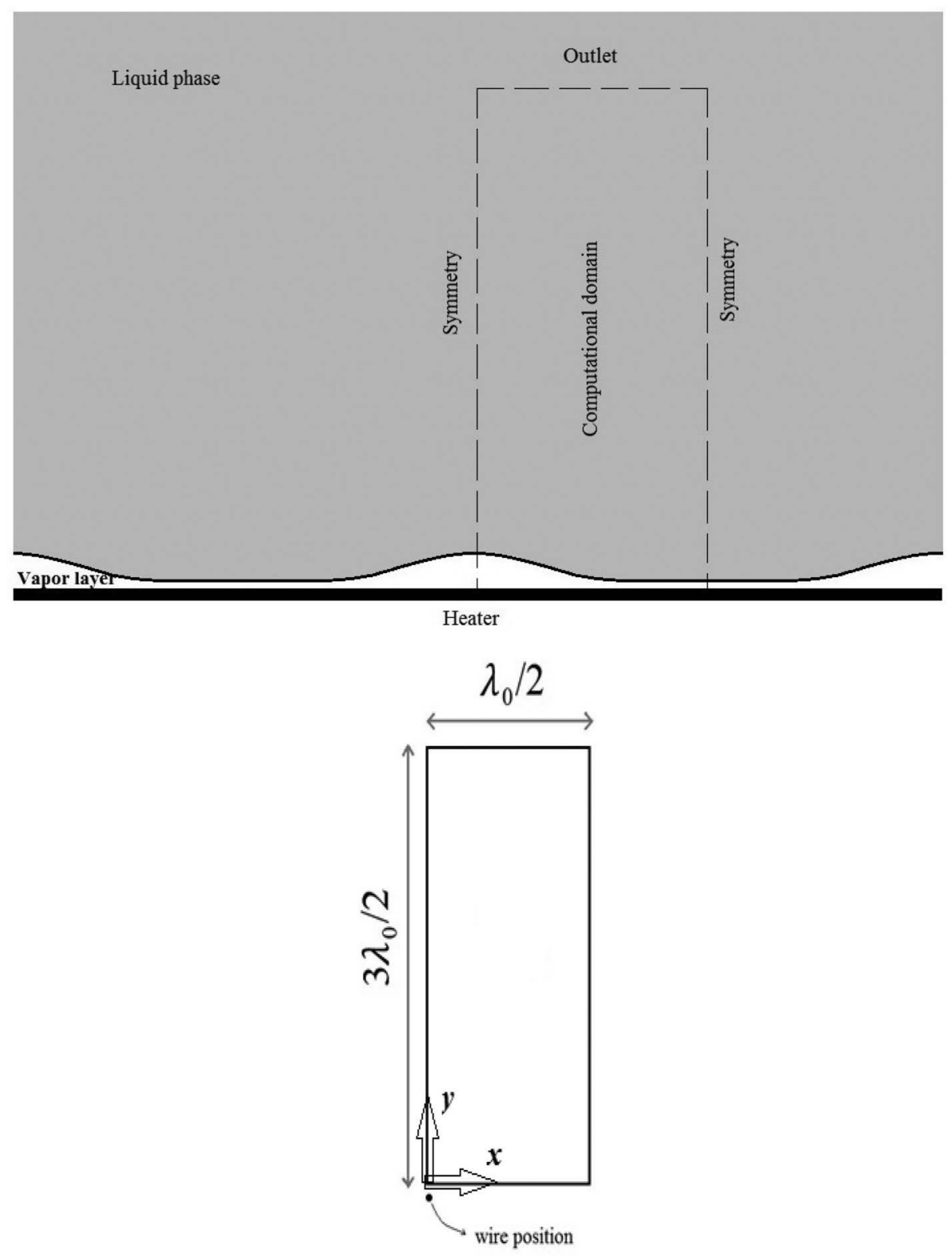

Figure 1 Studied geometry, boundary conditions, dimensions and wire position. 
The height and width of the computational domain are $3 \lambda_{0} / 2$ and $\lambda_{0}$, respectively where $\lambda_{0}$ is the most dangerous Taylor wave length and is as follows:

$$
\lambda_{0}=2 \pi \sqrt{\frac{3 \sigma}{\left(\rho_{l}-\rho_{v}\right) g}}
$$

The initial vapor film thickness on the horizontal plate has been considered according to below equation:

$$
\delta=\frac{\lambda_{0}}{128}\left(4+\cos \left(\frac{2 \pi x}{\lambda_{0}}\right)\right)
$$

The maximum and minimum initial film thickness is in $x=0$ and $x=$ $\lambda_{0} / 2$, respectively and only half of the wave length has been considered in this study, as seen from Figure 1.

\subsubsection{Boundary conditions}

Left and right side of the domain has been considered as symmetry boundary conditions:

$$
\begin{aligned}
& x=0: \quad u=0 . \quad \frac{\partial u}{\partial x}=\frac{\partial v}{\partial x}=0 \\
& x=\frac{\lambda_{0}}{2}: \quad u=0 . \quad \frac{\partial u}{\partial x}=\frac{\partial v}{\partial x}=0
\end{aligned}
$$

The boundary at top of the domain has been considered as outflow:

$$
y=\frac{3 \lambda_{0}}{2}: \quad \frac{\partial u}{\partial y}=\frac{\partial v}{\partial y}=\frac{\partial T}{\partial y}=0 . \quad P=P_{0}
$$

Bottom boundary has been set as a wall with a constant temperature well above the saturation temperature of the liquid where film boiling will occur:

$$
y=0: \quad T_{\text {wall }}=T_{\text {sat }}+\triangle T_{\text {sup }}
$$

\subsection{Correlations for Magnetic Field and Ferrofluid Properties}

The magnetic field in this study is generated by an electric current going through a straight wire located at the bottom of the heated plate as shown in Figure 1(b) and the current flows in the direction of negative $z$-axis in right-handed coordinate system. Below correlations were used for computing 
magnetic field components in the $x$ and $y$ directions [26]:

$$
\begin{aligned}
& H_{x}(x \cdot y)=\frac{I}{2 \pi} \frac{(x-a)}{(x-a)^{2}+(y-b)^{2}} \\
& H_{y}(x \cdot y)=-\frac{I}{2 \pi} \frac{(y-b)}{(x-a)^{2}+(y-b)^{2}}
\end{aligned}
$$

The magnitude of the magnetic field intensity can be calculated as:

$$
H(x \cdot y)=\frac{I}{2 \pi} \frac{1}{\sqrt{(x-a)^{2}+(y-b)^{2}}}
$$

In order to consider the effect of magnetic field on the film boiling behavior of ferrofluids, a source term has been added into the momentum equation which is as follows:

$$
\mu_{0}(\vec{M} \nabla) \vec{H}
$$

This term is so-called the Kelvin force density, derived from the stress of an electromagnetic field where $M$ is the magnetization and is defined as [27]:

$$
M=M_{s} L(\xi)=\frac{6 \alpha_{p} m_{p}}{\pi d_{p}^{3}}\left(\cot (\xi)-\frac{1}{\xi}\right)
$$

The unit cell of the crystal structure of magnetite has a volume of about $730 \AA^{3}$ and contains 8 molecules $\mathrm{Fe}_{3} \mathrm{O}_{4}$ and each of them having a magnetic moment of $4 \mu_{B}$ [28]. Therefore, the particle magnetic moment for the magnetite particles is obtained as:

$$
m_{p}=\frac{4 \mu_{B} \pi d_{p}^{3}}{6 \times 91.25 \times 10^{-30}}
$$

also $\xi$ is the Langevin parameter and is defined as [27]:

$$
\xi=\frac{\mu_{0} \mathrm{~m}_{\mathrm{p}} \mathrm{H}}{\mathrm{k}_{\mathrm{B}} \mathrm{T}}
$$

Langevin equation can be approximated as [29]:

$$
L(\xi)=\left(\operatorname{coth}(\xi)-\frac{1}{\xi}\right)=\frac{1}{3} \frac{\mu_{0} m_{p} H}{k_{B} T}
$$


In this study it is assumed that ferrofluid could be treated as single-phase liquid and its effective thermo-physical properties has been calculated by the following correlations:

density:

$$
\rho_{m}=\alpha_{P} \rho_{p}+\left(1-\alpha_{P}\right) \rho_{l}
$$

heat capacity:

$$
\left(\rho c_{p}\right)_{m}=\alpha_{P}\left(\rho c_{p}\right)_{p}+\left(1-\alpha_{P}\right)\left(\rho c_{p}\right)_{l}
$$

dynamic viscosity [11]:

$$
\mu_{m}=\left(1+\frac{5}{2} \alpha_{p}\right) \mu_{l}
$$

thermal conductivity (Hamilton and Crosser model [30] for spherical nanoparticles):

$$
k_{m}=\left[\frac{k_{p}+2 k_{l}-2 \alpha_{p}\left(k_{l}-k_{p}\right)}{k_{p}+2 k_{l}+\alpha_{p}\left(k_{l}-k_{p}\right)}\right] k_{l}
$$

thermal expansion coefficient [31]:

$$
\beta_{m}=\left[\frac{1}{1+\frac{\left(1-\alpha_{p}\right) \rho_{l}}{\alpha_{p} \rho_{p}}} \frac{\beta_{p}}{\beta_{l}}+\frac{1}{1+\frac{\alpha_{p} \rho_{p}}{\left(1-\alpha_{p}\right) \rho_{l}}}\right] \beta_{l}
$$

The local Nusselt number has been obtained by:

$$
N u=\frac{\lambda^{\prime}}{\left(T_{\text {wall }}-T_{\text {sat }}\right)}\left(\frac{\partial T}{\partial y}\right)_{y=0}
$$

where $\lambda^{\prime}$ is the characteristic length scale:

$$
\lambda^{\prime}=\sqrt{\frac{\sigma}{\left(\rho_{l}-\rho_{v}\right) g}}
$$

\subsection{Numerical Method}

A set of coupled non-linear differential equations have been discretized with control volume technique using ANSYSFLUENT 18 software. The QUICK method has been used for the convective and diffusive terms while, the PISO procedure has been introduced for velocity-pressure coupling. 
Table 1 Range of studied effective parameters

\begin{tabular}{lccc}
\hline Parameter & Superheat (K) & $\begin{array}{c}\text { Nanoparticles } \\
\text { Concentration (\%) }\end{array}$ & $\begin{array}{c}\text { Magnetic } \\
\text { Field Intensity (I (A)) }\end{array}$ \\
\hline Studied values & 10,100 & $0,1,4$ & $0,200,400$ \\
\hline
\end{tabular}

When the cell is near the interface between two phases, the geometric reconstruction scheme is used. This scheme represents the interface between fluids using a piecewise-linear approach. It assumes that the interface between two fluids has a linear slope within each cell, and uses this linear shape for calculation of the advection of fluid through the cell faces.

Some assumptions have been considered during the simulation which is listed as follows:

- Ferrofluids has been treated as the single phase liquids.

- Adding nanoparticles has no effect on the thermophysical properties of the vapor phase.

- Deposition of nanoparticles on the heater surface has been neglected.

- Effect of magnetic field on the vapor phase and the interface between the phases has been neglected and only the effect of magnetic field on the liquid has been considered.

Effect of various parameters on film boiling characteristics have been studied in this paper. Superheat of heated wall, nanoparticles concentration and magnetic field intensity have been chosen as the most important parameters which can influence film boiling characteristics. A summary of studied range of these parameters is given in Table 1 .

\section{Results and Discussions}

\subsection{Validation and Grid Independency Tests}

In order to verify the used numerical procedure in this study, two cases have been validated with previous works. Firstly, one-dimensional Stefan problem has been simulated and compared with the exact analytical results of this problem. Some other numerical studies have used this problem for verification of their simulations such as reference [4]. Domain definition of Stefan problem and comparison of interface position between numerical and analytical results have been illustrated in Figures 2 and 3, respectively. Cases 1-3 correspond to three different saturation pressures (and consequently, three different density ratios $\left.\left(\rho_{l} / \rho_{v}\right)\right)$ which are given in Table 2. Good 


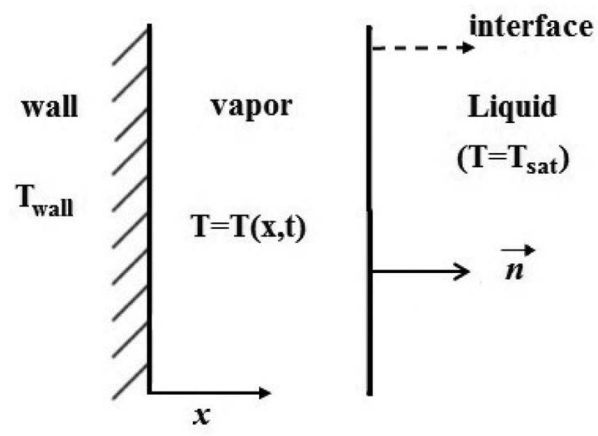

Figure 2 Domain definition of Stefan problem [4].

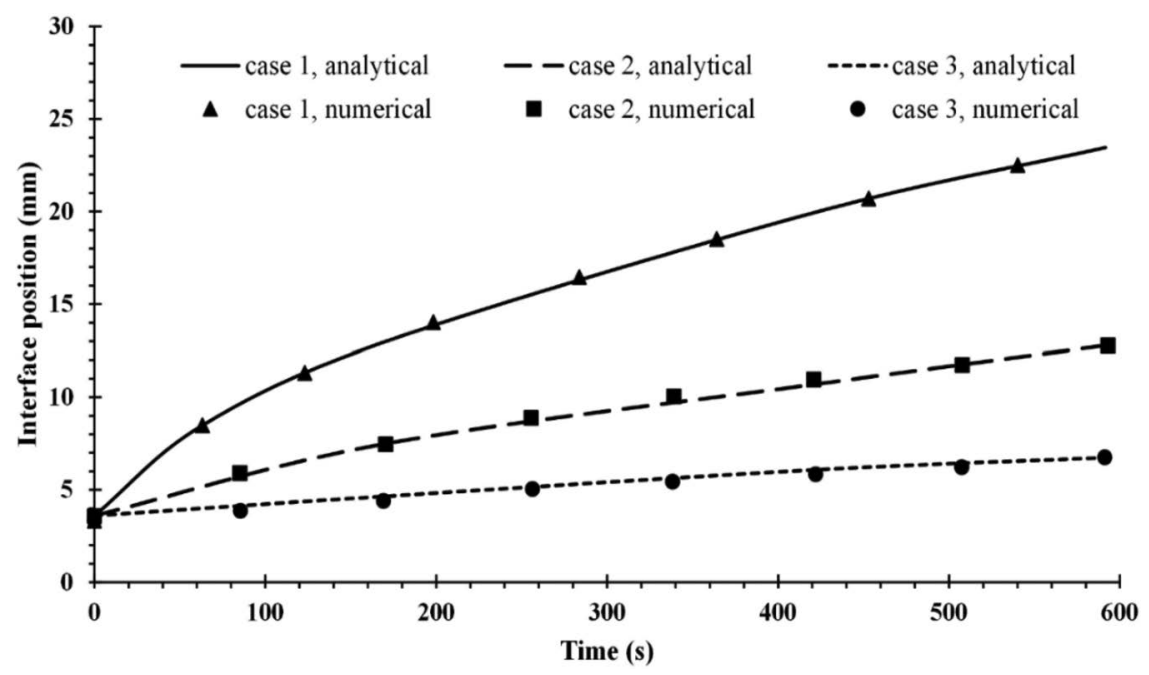

Figure 3 Comparison of numerical simulation with analytical results of Stefan problem.

Table 2 Studied cases in Stefan problem

\begin{tabular}{lcc}
\hline Case & Pressure $(\mathrm{kPa})$ & Density Ratio $\left(\rho_{l} / \rho_{v}\right)$ \\
\hline 1 & 101.3 & 1624 \\
2 & 571 & 301 \\
3 & 14044 & 7 \\
\hline
\end{tabular}

agreement between our numerical results and existent analytical results is seen from Figure 3.

The second case of validation is the comparison of obtained $\mathrm{Nu}$ number for horizontal film boiling with the correlations of Berenson [32] 
and Klimenko [33]. These correlations are the most widely accepted for horizontal film boiling. Berenson's expression for $\mathrm{Nu}$ is as follows:

$$
N u=0.425\left(\frac{\rho_{v}\left(\rho_{l}-\rho_{v}\right) g h_{l v}}{k_{v} \mu_{v}\left(T_{\text {wall }}-T_{\text {sat }}\right)}\right)^{1 / 4}\left(\lambda^{\prime}\right)^{3 / 4}
$$

Klimenko's correlation for $\mathrm{Nu}$ is expressed as follows:

$$
N u= \begin{cases}0.19 \times G r^{1 / 3} \mathrm{Pr}^{1 / 3} f_{1} & \text { for } G r<4.03 \times 10^{5} \\ 0.0216 \times G r^{1 / 2} \operatorname{Pr}^{1 / 3} f_{2} & \text { for } G r>4.03 \times 10^{5}\end{cases}
$$

where

$$
\begin{aligned}
& f_{1}= \begin{cases}1 & \text { for } \beta>0.71 \\
0.89 \beta^{-1 / 3} & \text { for } \beta<0.71\end{cases} \\
& f_{2}= \begin{cases}1 & \text { for } \beta>0.5 \\
0.71 \beta^{-1 / 2} & \text { for } \beta<0.5\end{cases}
\end{aligned}
$$

In the above equations the Grashof number, Prandtl number and $\beta$ can be expressed as:

$$
\begin{aligned}
G r & =\frac{\rho_{v}^{2} g \lambda^{\prime 3}}{\mu_{v}^{2}}\left(\frac{\rho_{l}}{\rho_{v}}-1\right) \\
\operatorname{Pr} & =\frac{C_{p v} \mu_{v}}{k_{v}} \\
\beta & =\frac{c_{p v}\left(T_{w a l l}-T_{s a t}\right)}{h_{l v}}
\end{aligned}
$$

The base fluid properties have been summarized in Table 3. Comparison of the obtained results from numerical simulations with those calculated from these correlations is shown in Figure 4. Space and time averaged $\mathrm{Nu}$ from numerical simulations is about 3.35 which is between the values calculated from Klimenko correlation (3.27) and Berenson correlation (3.92).

Table 3 Thermophysical properties of the base fluid

\begin{tabular}{lcc}
\hline Case & Liquid & Vapor \\
\hline Density $\left(\mathrm{kg} / \mathrm{m}^{3}\right)$ & 200 & 5 \\
Heat capacity $(\mathrm{J} / \mathrm{kgK})$ & 400 & 200 \\
Thermal conductivity $(\mathrm{W} / \mathrm{m} \cdot \mathrm{K})$ & 40 & 1 \\
Viscosity $(\mathrm{Pa} \cdot \mathrm{s})$ & 0.1 & 0.005 \\
\hline
\end{tabular}




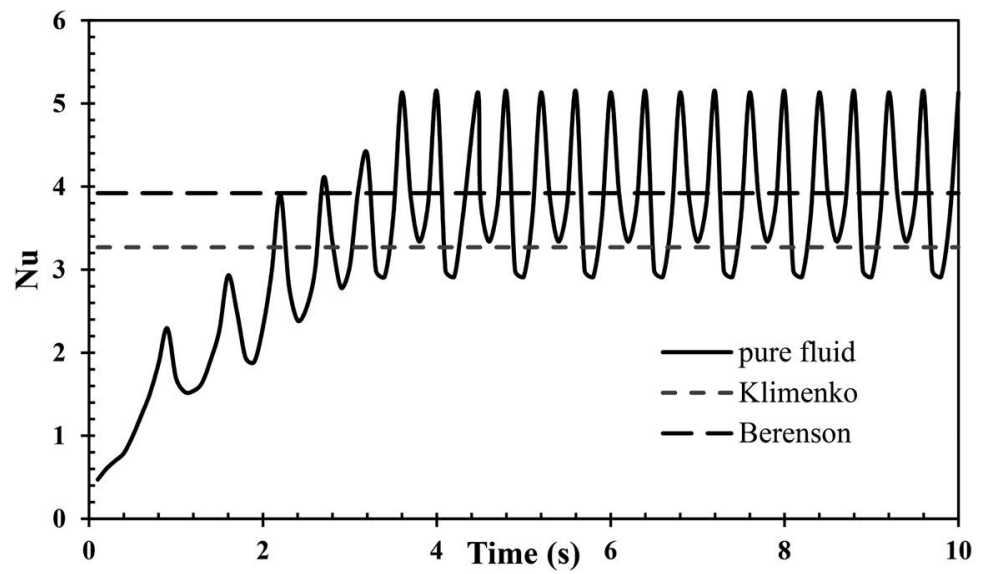

Figure 4 Comparison of numerical simulation with correlations of Berenson and Klimenko.

Several different grid distributions have been examined for checking the grid independency of the obtained results. This grid independency is illustrated graphically in Figure 5. As shown in this figure, increasing the grid numbers between the second and third type of grids does not change significantly the vapor film profile. Therefore the computational domain has been divided into $64 \times 192$ uniform grids in the $x$ and $y$ directions, respectively.

\subsection{Ferrofluid Film Boiling}

Figures 6 and 7 show film growing and detachment of three different fluids at various times in wall superheat of 10 and 100, respectively.

Initial film is growing by time and finally, it detaches from the heated surface. By comparison of this phenomenon in three different fluids, it is evident that film growing and detachment mechanism is enhanced by adding nanoparticles into the base fluid. By increasing the wall superheat from 10 to 100 , the manner of vapor film growing and detachment has changed and vapor bubble columns has been created, as it is expected with referring to the previous studies $[3,34]$.

The first thing which comes into the mind for changing of the film boiling characteristics with adding nanoparticles into the base fluid is the changes in thermo-physical properties of the base fluid. As we know, dispersing nanoparticles into the pure fluid increases density, thermal conductivity and viscosity and decreases thermal heat capacity. 


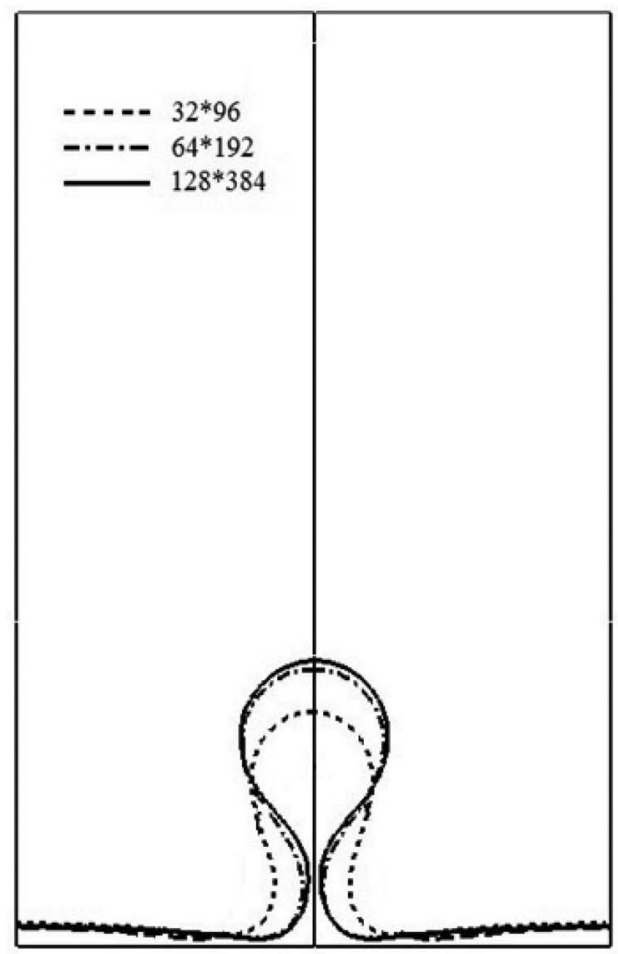

Figure 5 Grid independency study.

There are several parameters effecting vapor film growing and detachment such as surface tension, buoyancy, etc. Concluding from literature review, one of the most import parameters effecting the two-phase flows, is the density ratio of the phases. By adding the nanoparticles into the base fluid, liquid density increases and with assuming of no change in the vapor density, liquid to vapor density ratio will be increased and this can be the reason of the observed results. For detailed study of the effect of this parameter on the film boiling characteristics, a simulation of film boiling of $4 \%$ ferrofluid was made again but with no change in the density of liquid phase with respect to the base fluid. In the other words, the density of the ferrofluid was kept equal to the base fluid one. The obtained results were illustrated in Figures 8 and 9.

As seen from these figures, the results of ferrofluid film boiling in this case are very similar to the base fluid ones. Therefor it can be concluded that the major parameter effecting film boiling of ferrofluids is the liquid to vapor density ratio. A similar result has been obtained in Stefan problem 
$\mathrm{t}(\mathrm{s})$

0.4

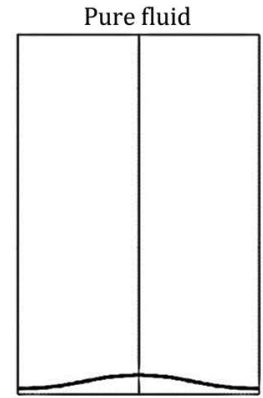

0.6

0.8

1
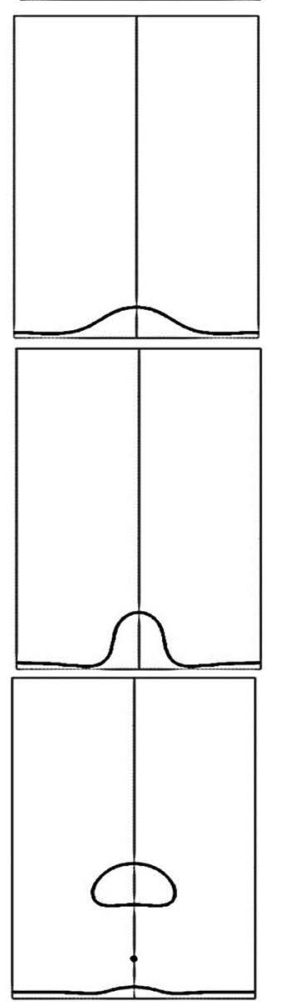

$1 \%$ ferrofluid
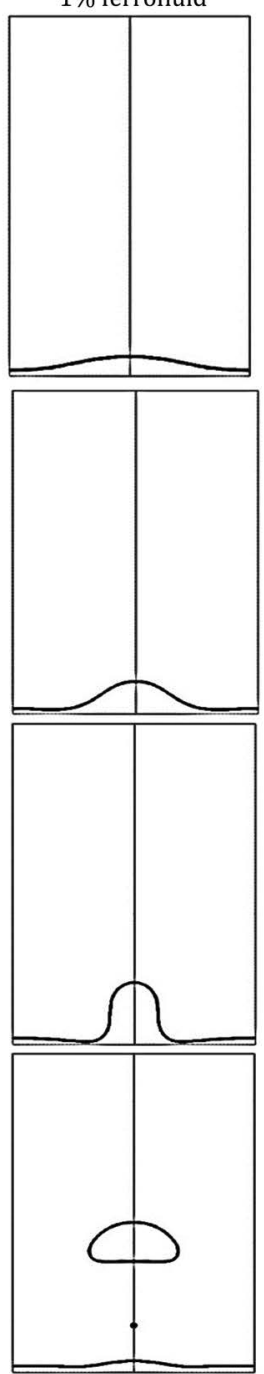

$4 \%$ ferrofluid
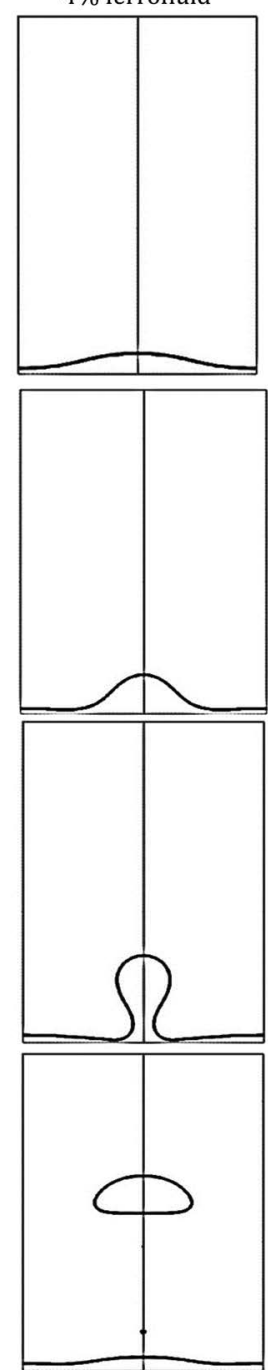

Figure 6 Comparison of pure fluid and ferrofluids $\left(\triangle T_{\text {sup }}=10\right)$.

(see Figure 3) where with increasing liquid to vapor density ratio, an increase in interface diffusion to the liquid phase has been observed that is in good agreement with our results. In order to study the effect of ferrofluids on film boiling heat transfer, comparison of $\mathrm{Nu}$ number between pure and ferrofluids have been illustrated in Figure 10. 

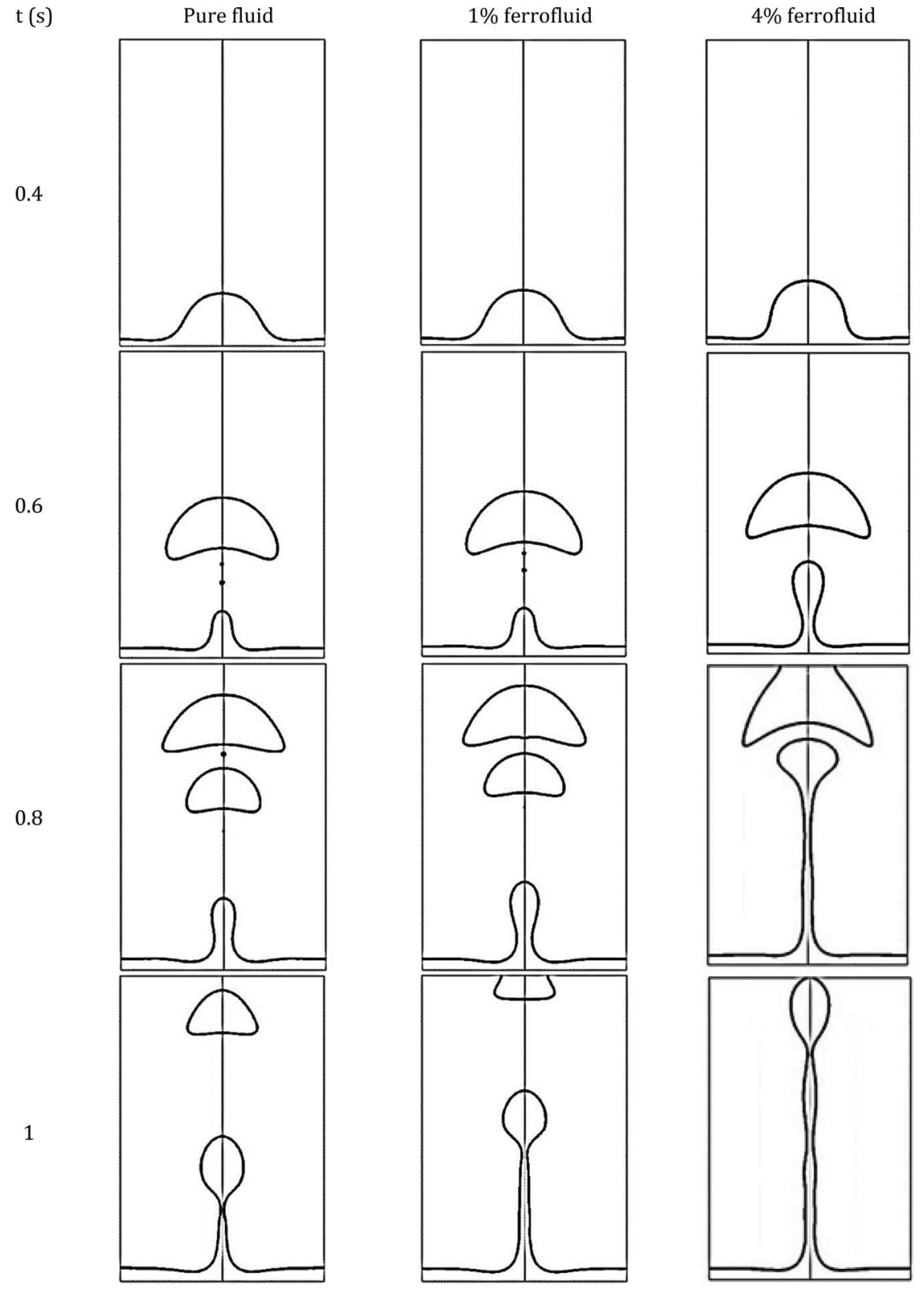

Figure 7 Comparison of pure fluid and ferrofluids $\left(\triangle T_{\text {sup }}=100\right)$. 
Non-Uniform Magnetic Field Effects on Ferrofluids Film Boiling 651

$t(s)$

Pure fluid

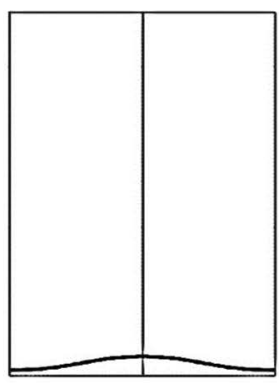

0.8

1
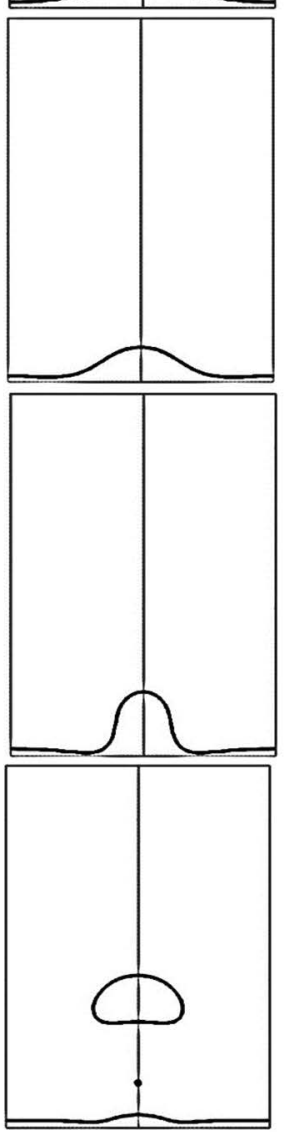

$4 \%$ ferrofluid
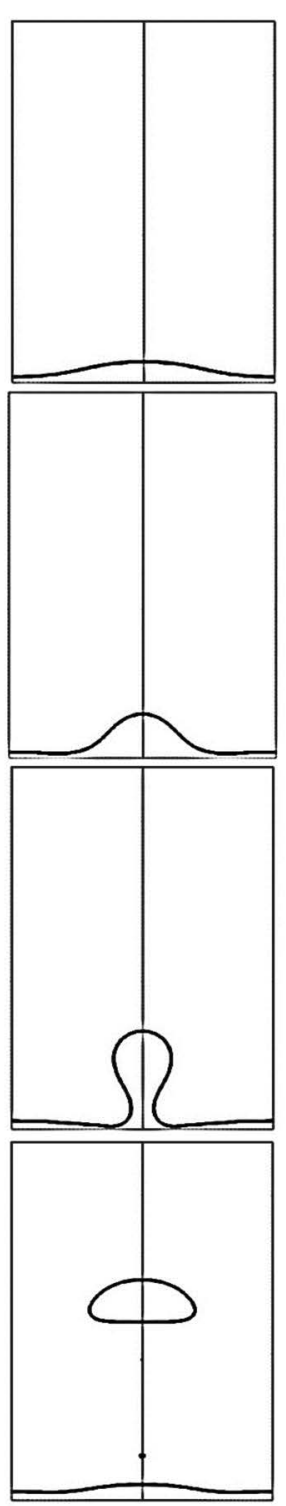

$4 \%$ ferrofluid

(pure fluid density)

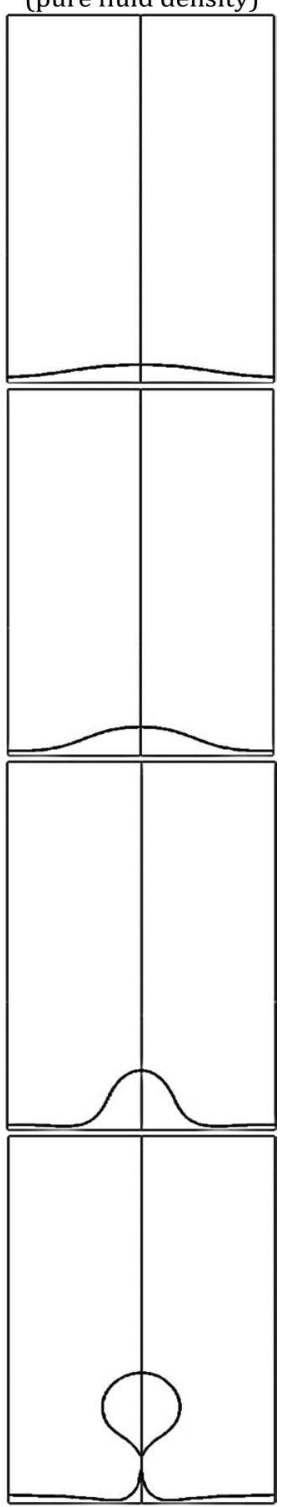

Figure 8 Effect of density on film boiling $\left(\triangle T_{\text {sup }}=10\right)$. 
$\mathrm{t}(\mathrm{s})$

Pure fluid

$4 \%$ ferrofluid

$4 \%$ ferrofluid

(pure fluid density)

0.4
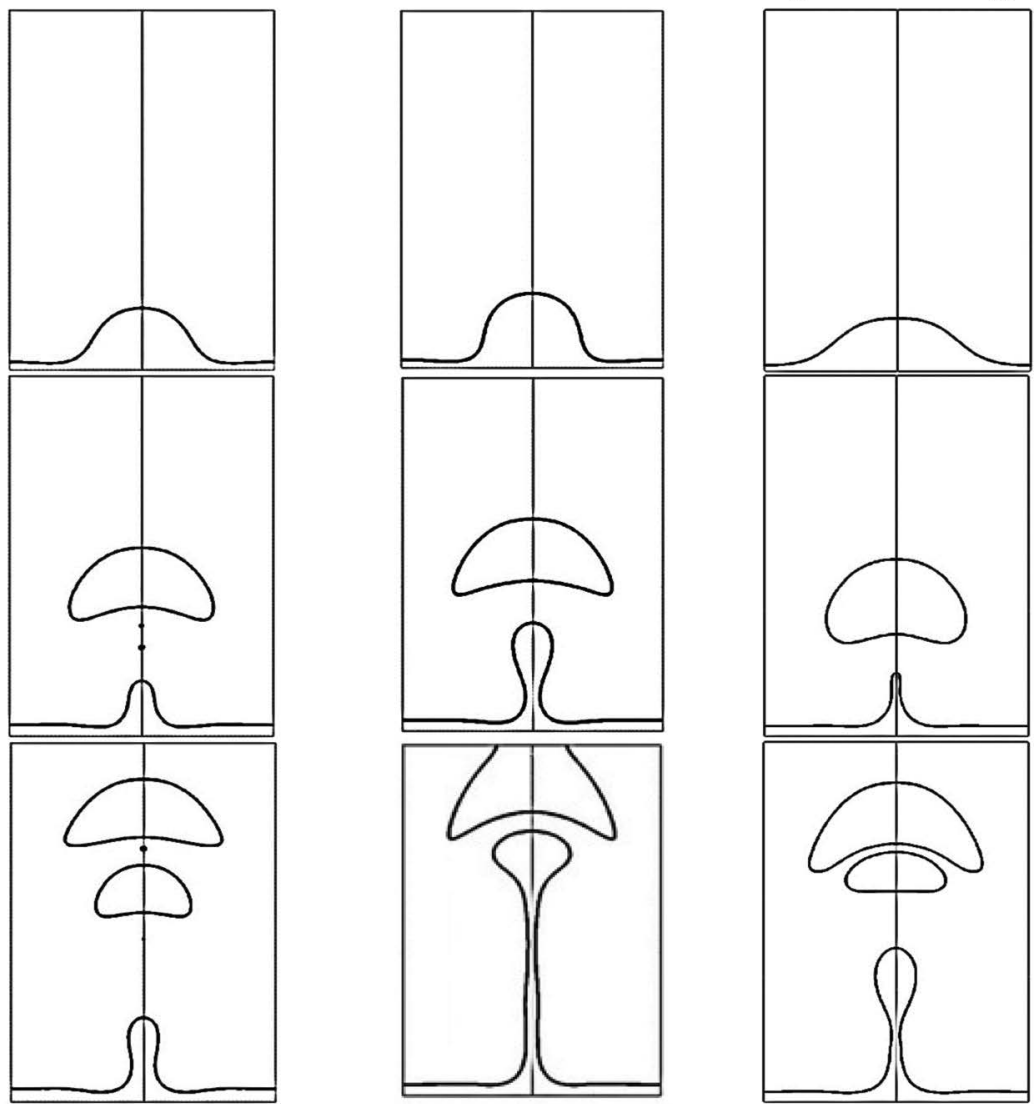

0.8
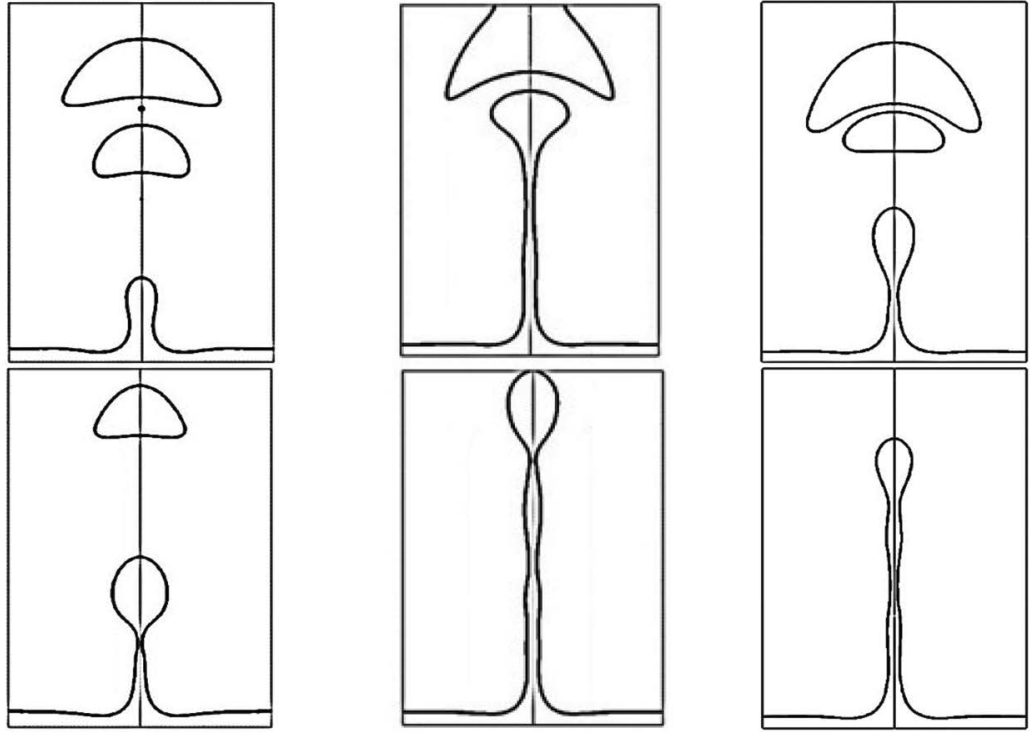

Figure 9 Effect of density on film boiling $\left(\triangle T_{\text {sup }}=100\right)$. 


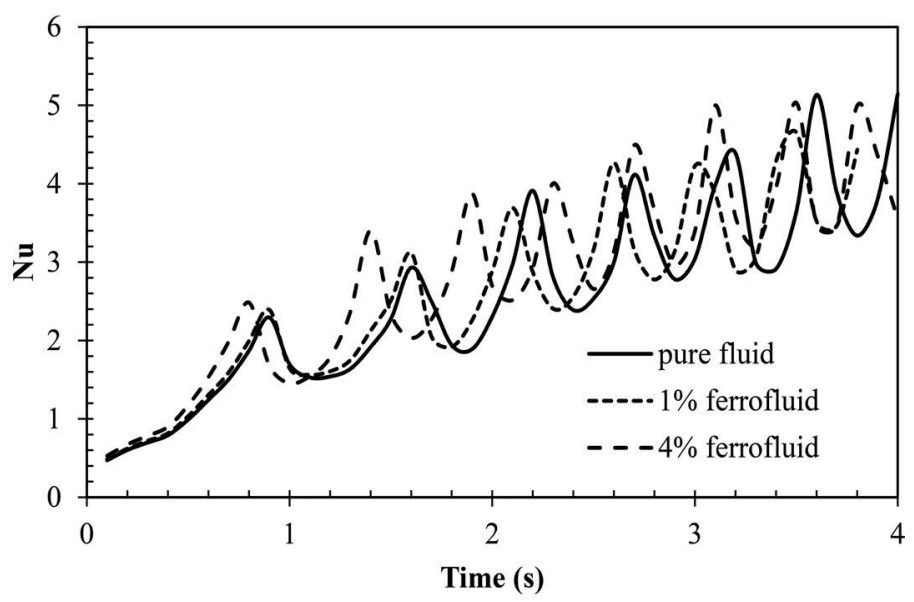

(a)

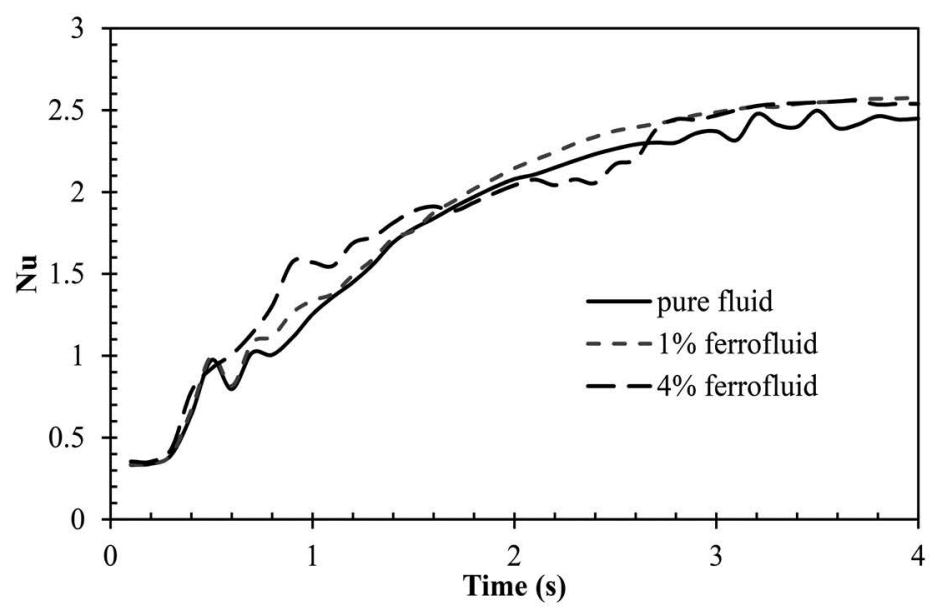

(b)

Figure 10 Heat transfer comparison between pure fluid and ferrofluids: (a) $\triangle T_{\text {sup }}=10$, and (b) $\triangle T_{\text {sup }}=100$.

It can be concluded from this figure that, according to the previous discussions, heat transfer diagrams of ferrofluids have shifted to the left due to the rapid growing and detachment of vapor bubbles with respect to pure fluid. For detailed study, time averaged $\mathrm{Nu}$ number has been calculated and was illustrated in Figure 11. As seen, adding nanoparticles into the base fluid increased heat transfer in film boiling in both superheats. 


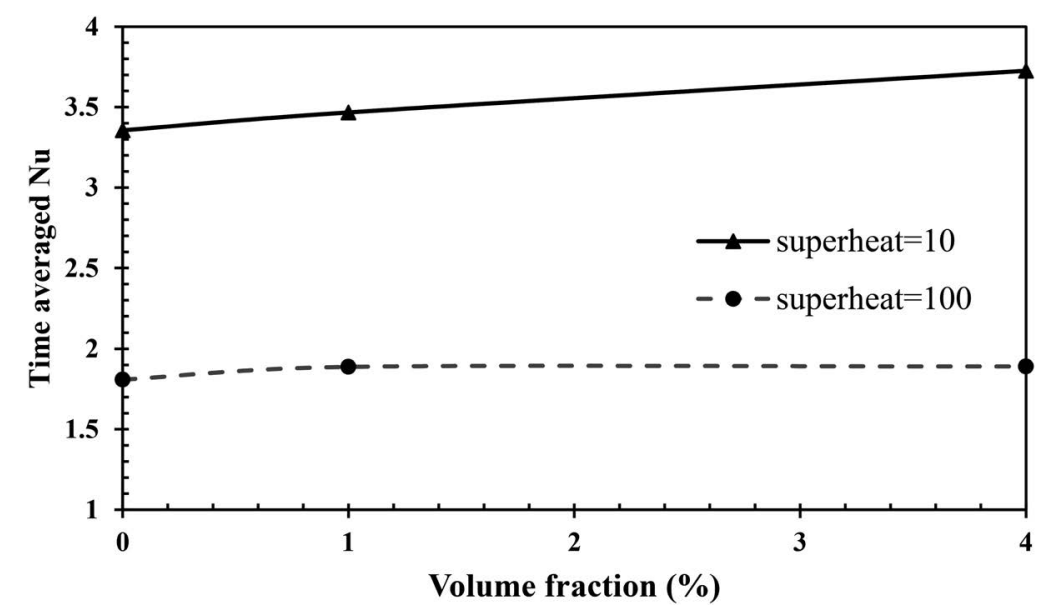

Figure 11 Effect of nanoparticle volume fraction and wall superheat on time averaged $\mathrm{Nu}$ number.

\subsection{Effect of Magnetic Field on Ferrofluids Film Boiling}

In this section, the effects of transvers magnetic field with two different intensities on the film boiling characteristics have been studied. These investigations have been made for two heated wall superheats. Figures 12 and 13 show vapor film growing and detachment for 1 and 4 percent of nanoparticles in wall superheat of 10 , respectively.

For $1 \%$ ferrofluid, magnetic field with lower intensity (i.e. $\mathrm{I}=200$ ) has negligible effect on vapor film profile but by increasing the magnetic field intensity, remarkable changes have been observed. These changes are more noticeable in $4 \%$ ferrofluid in both magnetic field intensities. Applying transverse magnetic fields exerts an upward force to the liquid above the vapor film which causes rapid vapor film growing. Consequently, the vapor film growing and detachment will be accelerated. These effects are higher for $4 \%$ ferrofluid.

Similar discussions are valid for wall superheat of 100 (see Figures 14 and 15).

Effect of magnetic field on heat transfer in film boiling have been shown in Figures 16 and 17. As seen in these figures, application of transvers magnetic fields increases heat transfer in horizontal film boiling which 
Non-Uniform Magnetic Field Effects on Ferrofluids Film Boiling 655

$\mathrm{t}(\mathrm{s})$

0.4

0.6

0.8

1
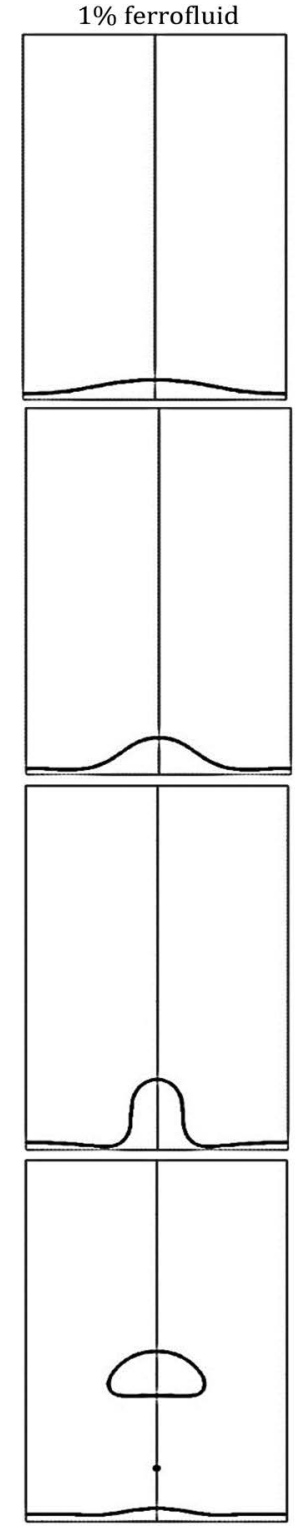
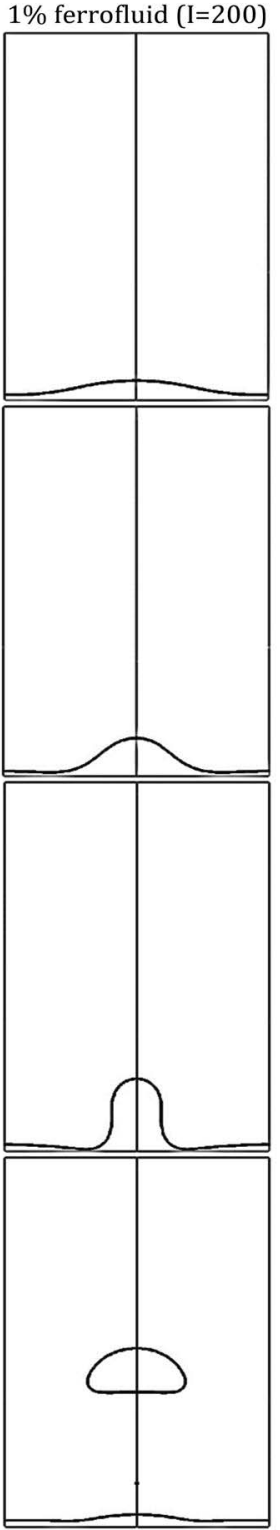

$1 \%$ ferrofluid $(\mathrm{I}=400)$

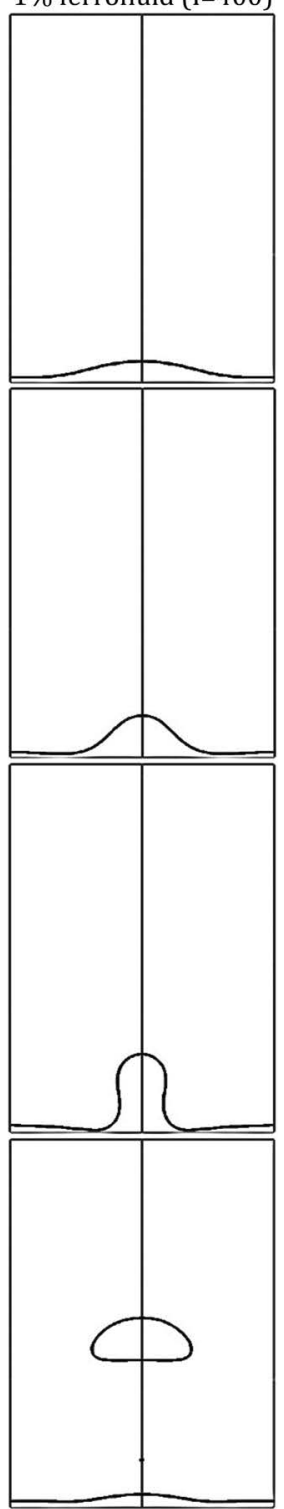

Figure 12 Comparison of magnetic fields in $1 \%$ ferrofluids $\left(\triangle T_{\text {sup }}=10\right)$. 

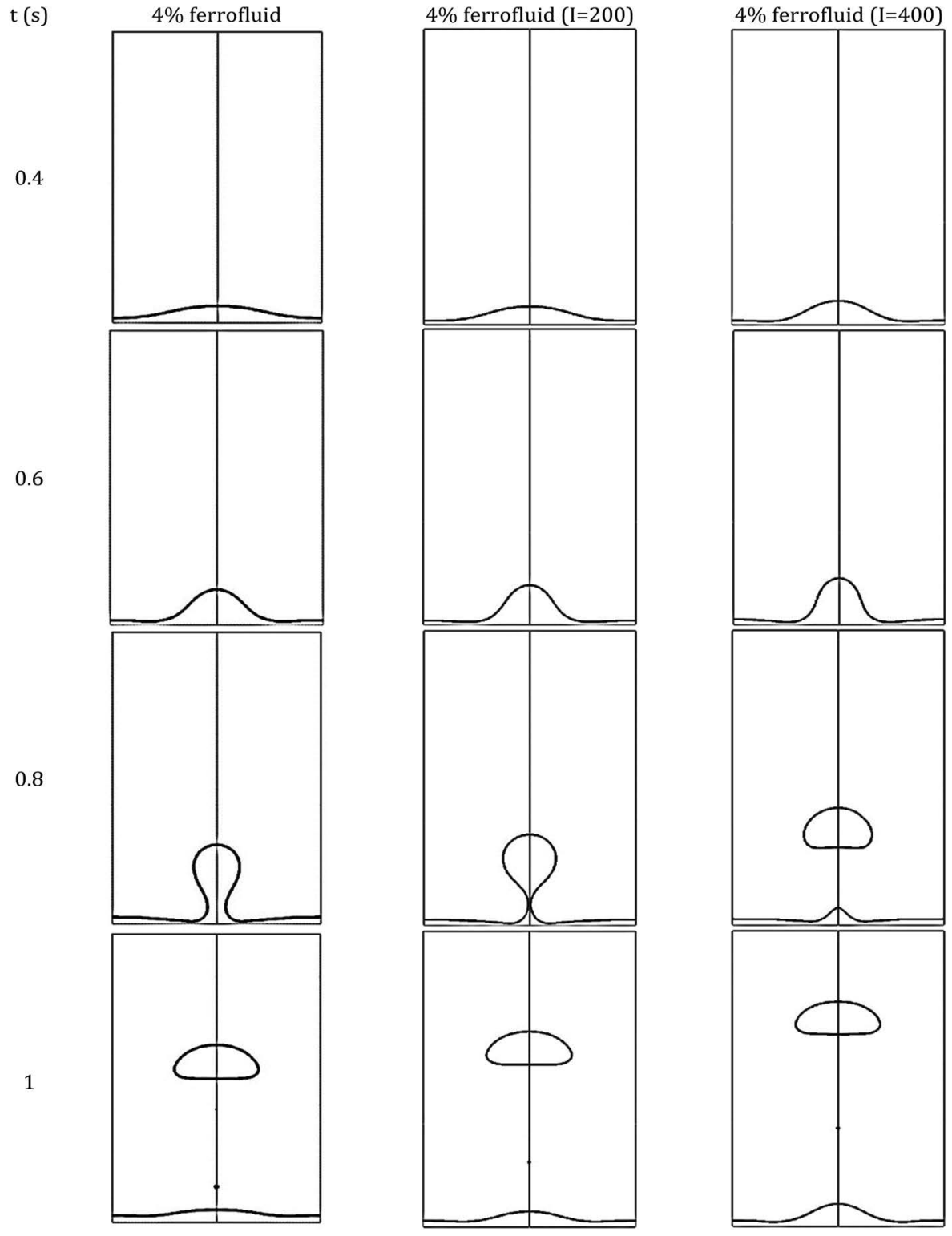

Figure 13 Comparison of magnetic fields in $4 \%$ ferrofluids $\left(\triangle T_{\text {sup }}=10\right)$. 
Non-Uniform Magnetic Field Effects on Ferrofluids Film Boiling 657

$\mathrm{t}(\mathrm{s})$

0.4

0.6

0.8

1
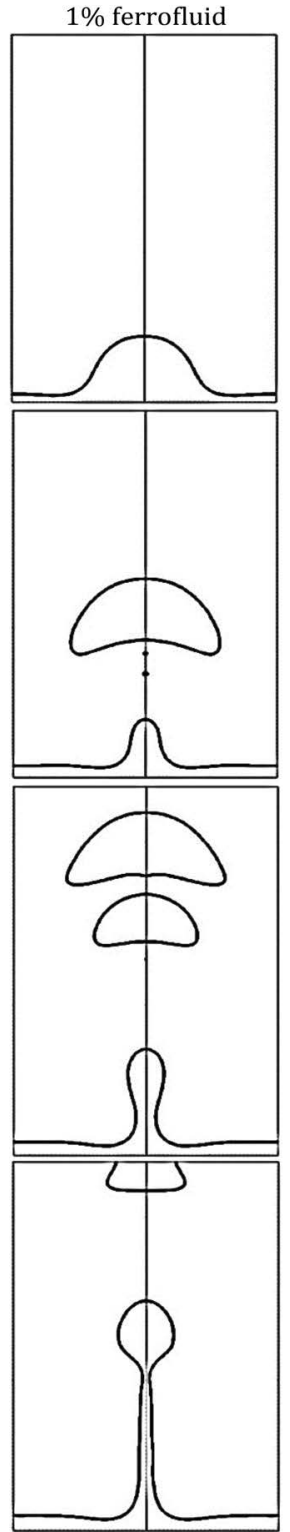

$1 \%$ ferrofluid $(\mathrm{I}=200)$
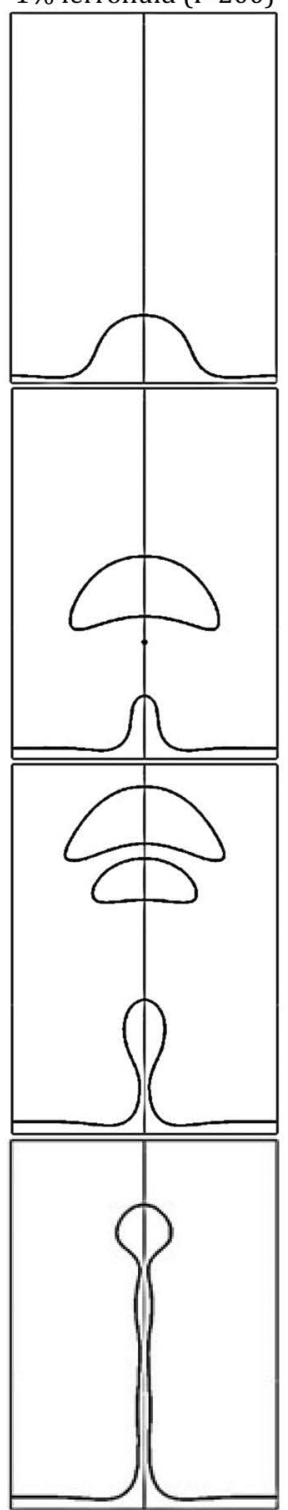

$1 \%$ ferrofluid ( $\mathrm{I}=400)$

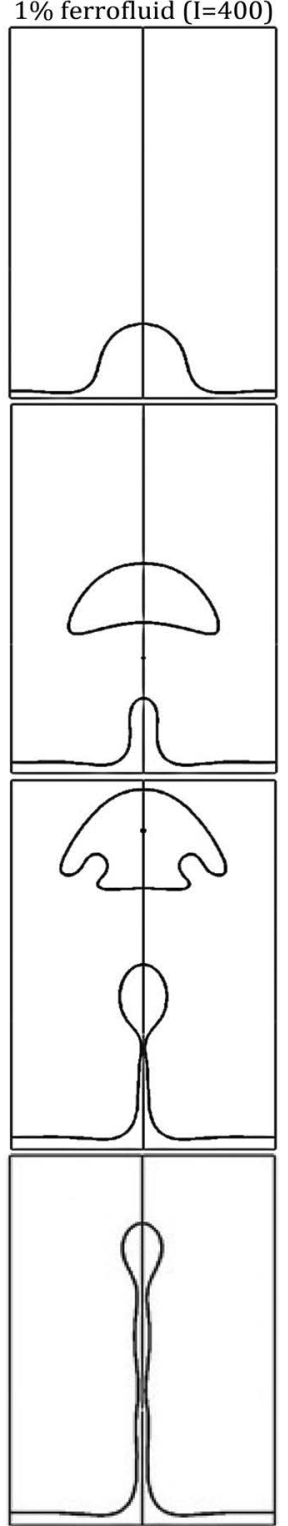

Figure 14 Comparison of magnetic fields in $1 \%$ ferrofluids $\left(\triangle T_{\text {sup }}=100\right)$. 

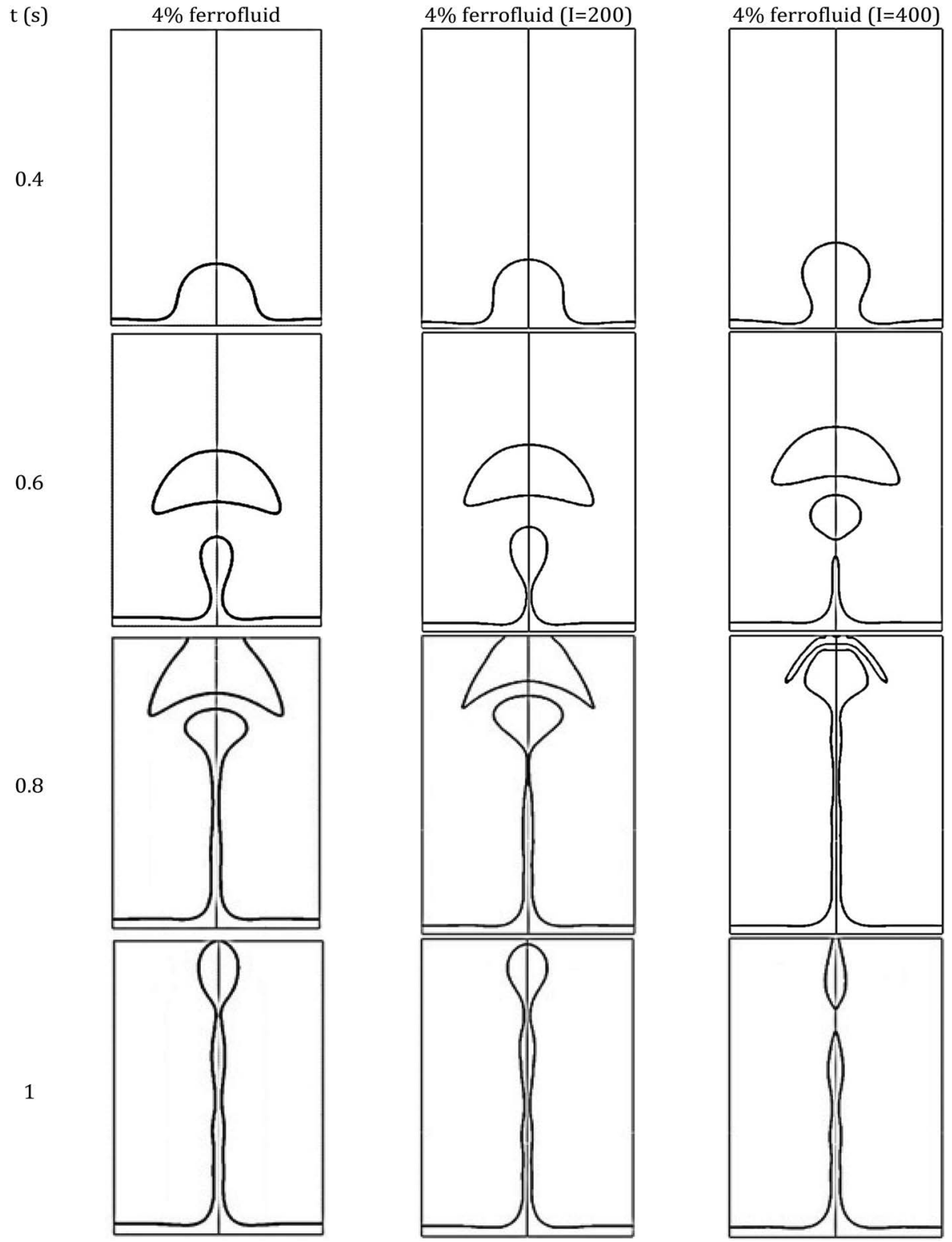

Figure 15 Comparison of magnetic fields in $4 \%$ ferrofluids $\left(\triangle T_{\text {sup }}=100\right)$. 


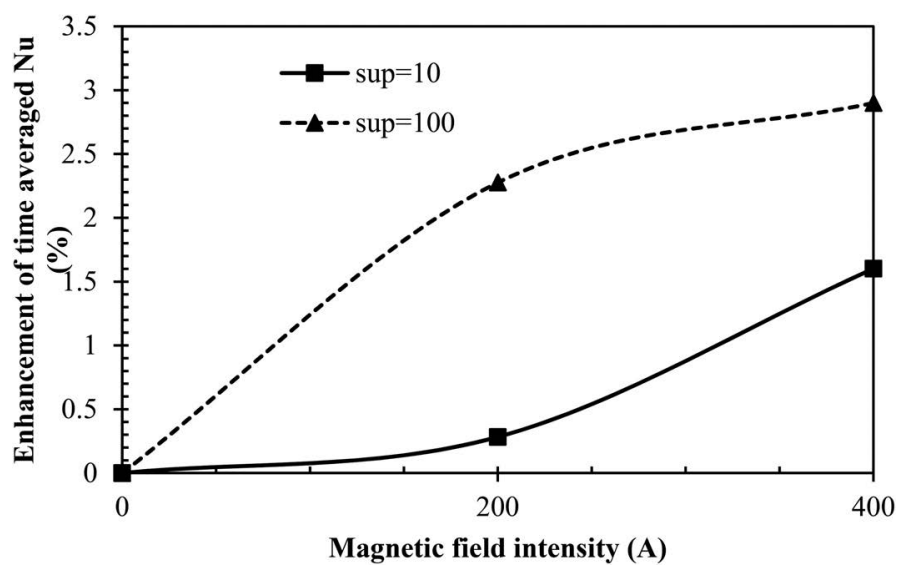

Figure 16 Effect of magnetic field on time averaged $\mathrm{Nu}$ number (1\% ferrofluid).

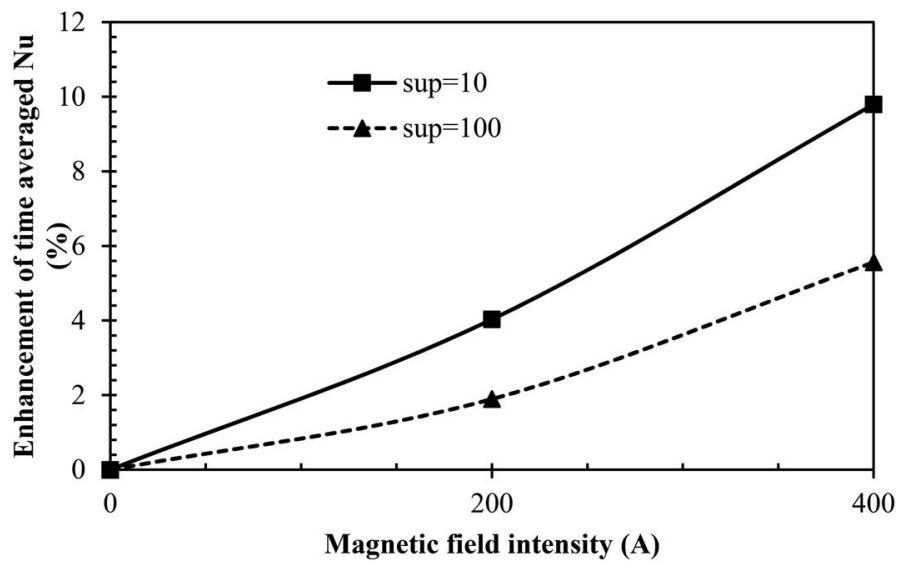

Figure 17 Effect of magnetic field on time averaged $\mathrm{Nu}$ number (4\% ferrofluid).

these effects are more notable at higher magnetic field intensity and higher nanoparticle volume fractions. Maximum heat transfer enhancement of 3\% and $10 \%$ at higher magnetic field intensity is seen for $1 \%$ and $4 \%$ ferrofluids, respectively.

For detailed study of the effect of magnetic field on film boiling of $4 \%$ ferrofluid, velocity contours with and without application of external magnetic field were illustrated in Figure 18. 


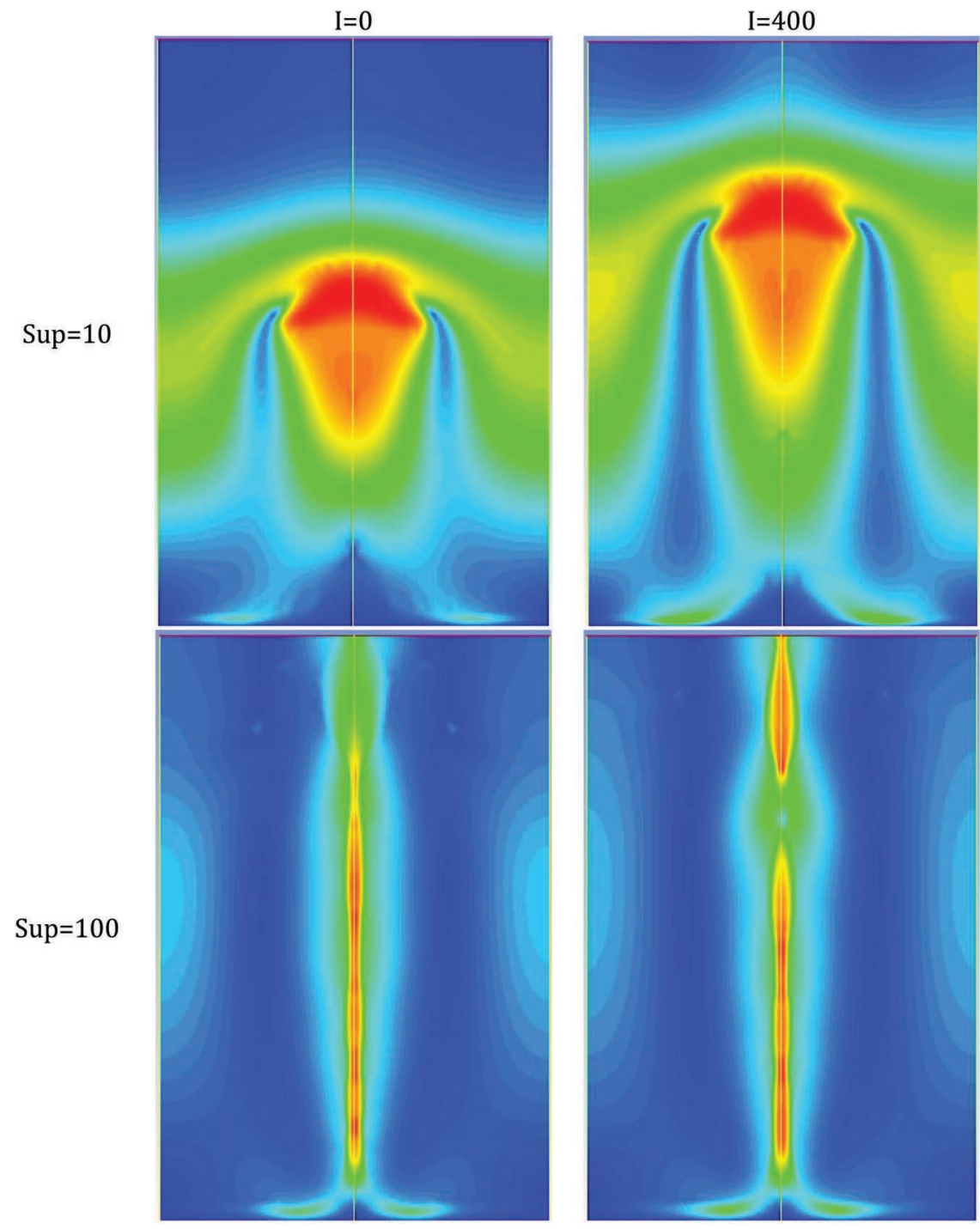

Figure 18 Velocity contours of $4 \%$ ferrofluid at $\mathrm{t}=1 \mathrm{~s}$.

It can be observed from these figure that application of magnetic field caused the velocity enhancement in the flow regime. For quantitative study of this finding, near wall velocity of this cases were illustrated in Figure 19.

It can be concluded from this figure that near wall velocities of the ferrofluid were increasedby application of an external magnetic field, and 


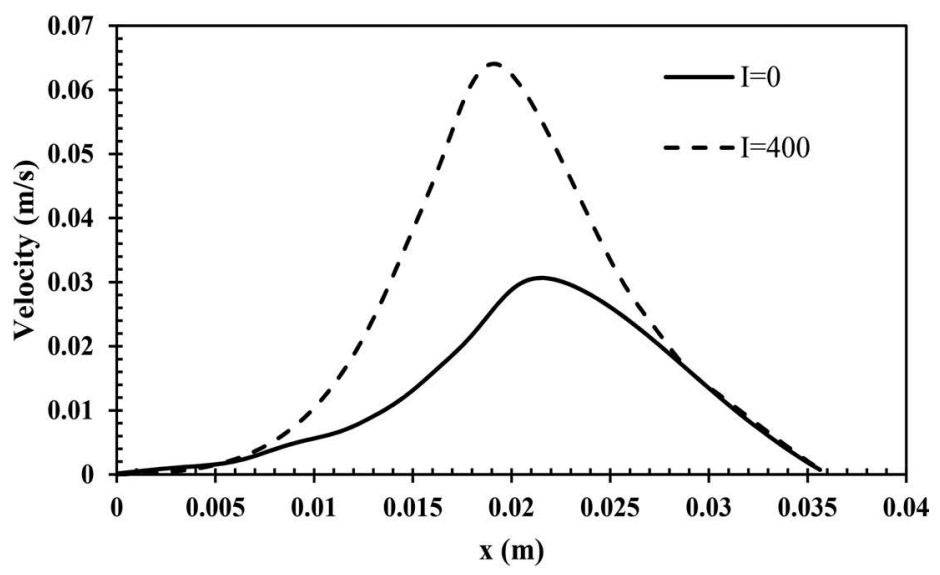

(a)

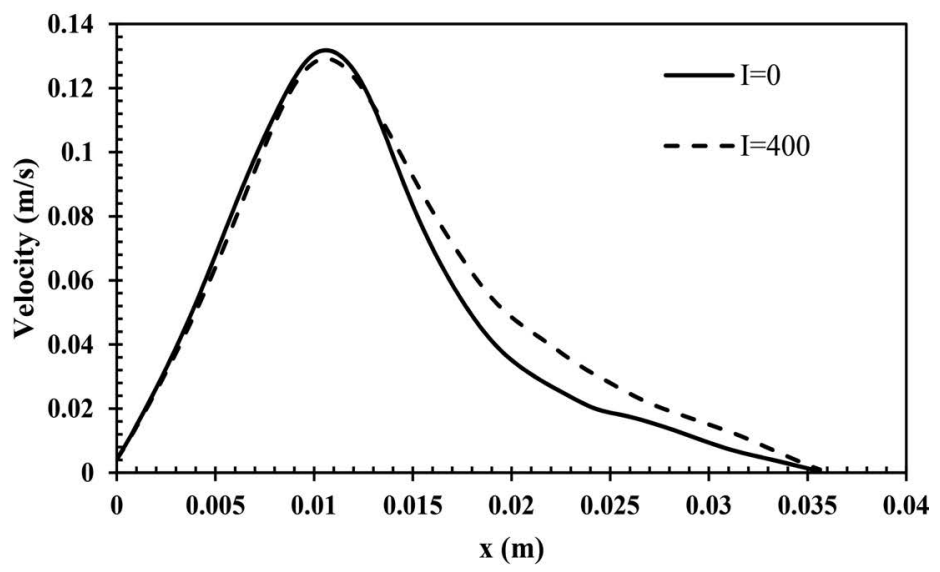

(b)

Figure 19 Near wall velocity of $4 \%$ ferrofluid at $t=1$ s: (a) $\sup =10$, (b) $\sup =100$.

this can be an important reason of film boiling heat transfer enhancement by application of the magnetic field.

\section{Conclusions}

Horizontal film boiling of pure fluid and ferrofluids with and without applying magnetic field has been studied numerically. PISO algorithm for pressure-velocity coupling and VOF method for interface capturing have 
been used. The applied numerical method has been verified by a onedimensional Stefan problem and also with two famous correlations for $\mathrm{Nu}$ number. Obtained results indicated that film growing and detachment process in ferrofluids was faster than pure fluid one, which is mainly due to the liquid to vapor density ratio enhancement by adding nanoparticles into the base fluid. Also, using ferrofluid as a working fluid enhanced $\mathrm{Nu}$ number with respect to pure fluid. Another important result from this study is the effect of magnetic field on the horizontal film boiling characteristics. Application of magnetic field with two different intensities enhanced vapor film growing and detachment. Also Nu number was enhanced by applying magnetic field. Maximum enhancement of averaged $\mathrm{Nu}$ number with application of magnetic field was $3 \%$ and $10 \%$ for $1 \%$ and $4 \%$ ferrofluids, respectively. Thus it is suggested that for the cases which the film boiling is inevitable, using ferrofluids and application of magnetic fields can improve heat transfer characteristics.

\title{
Nomenclature
}

\author{
$c_{p} \quad$ Specific heat capacity $(\mathrm{J} / \mathrm{kgK})$ \\ $d_{p} \quad$ Nanoparticle diameter $(m)$ \\ E Energy $(J)$ \\ $f \quad$ Surface stress \\ $F_{\text {st }} \quad$ Stress at the interface \\ $g \quad$ Gravitational acceleration $\left(\mathrm{m} / \mathrm{s}^{2}\right)$ \\ $\vec{H} \quad$ Magnetic field vector $(A / m)$ \\ $H_{x} \quad x$-component of magnetic field vector \\ $H_{y} \quad y$-component of magnetic field vector \\ $h \quad$ Height of studied domain $(m)$ \\ I Electric current (A) \\ $k \quad$ Thermal conductivity $(\mathrm{W} / \mathrm{m} \cdot \mathrm{K})$ \\ $k_{B} \quad$ Boltzmann constant $\left(1.3806503 \times 10^{-23} \mathrm{~J} / \mathrm{K}\right)$ \\ $L(\xi) \quad$ Langevin function \\ $M \quad$ Magnetization $(A / m)$ \\ $m_{p} \quad$ Particle magnetic moment $\left(A m^{2}\right)$ \\ $\dot{m} \quad$ Evaporation mass transfer rate $(\mathrm{kg} / \mathrm{s})$ \\ $\mathrm{Nu} \quad$ Nusselt number \\ $\vec{n} \quad$ Normal direction to interface \\ $P \quad$ Pressure $(\mathrm{Pa})$ \\ $S \quad$ Source term
}




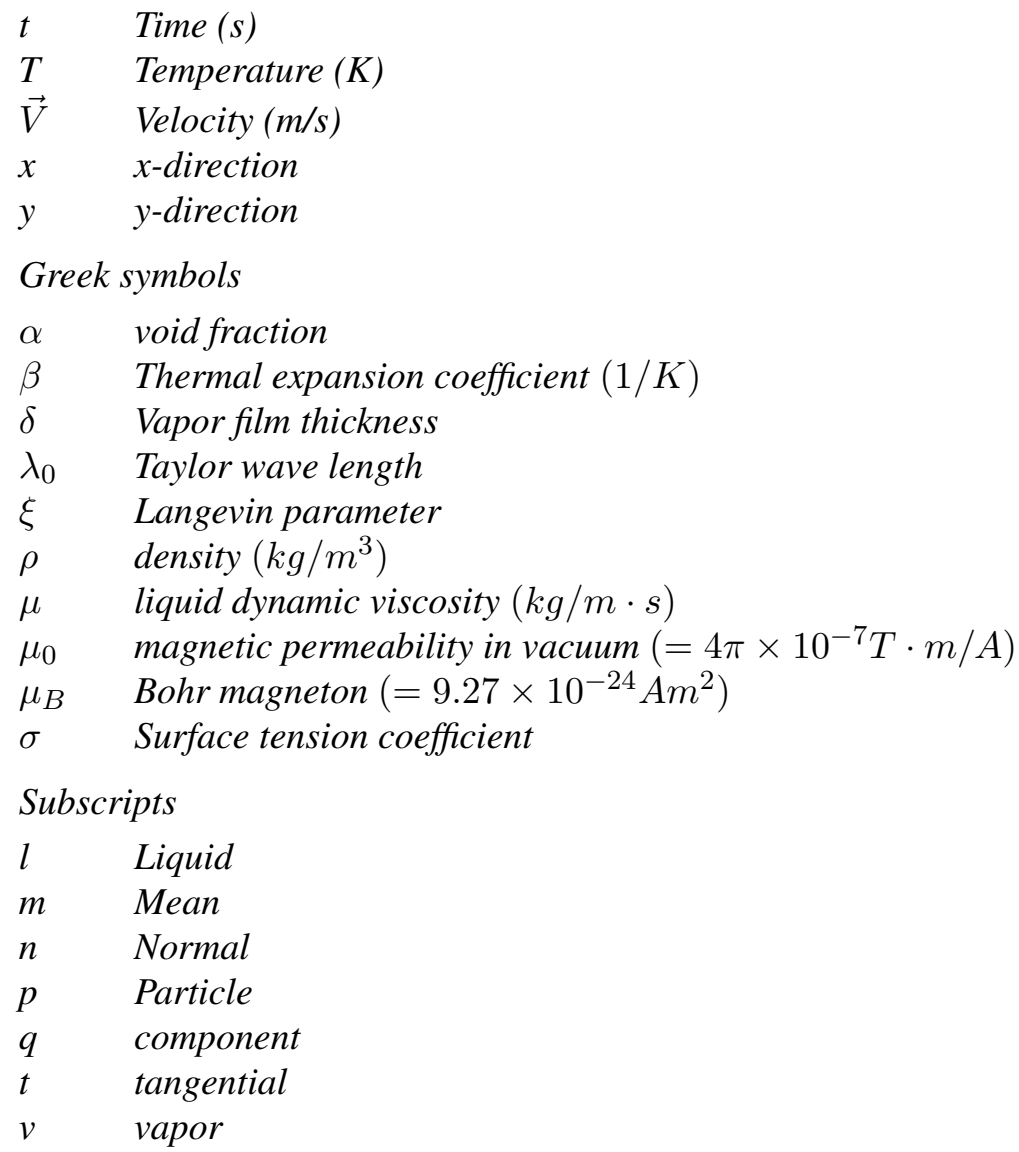

\section{References}

[1] Y. Y. Hsu, "A Review of Film Boiling at Cryogenic Temperatures," in Advances in Cryogenic Engineering: A Collection of Invited Papers and Contributed Papers Presented at National Technical Meetings During 1970 and 1971, K. D. Timmerhaus, Ed. Boston, MA: Springer US, 1972, pp. 361-381.

[2] J. C. Y. Koh, "Analysis of Film Boiling on Vertical Surfaces," Journal of Heat Transfer, vol. 84, no. 1, pp. 55-62, 1962.

[3] G. Son and V. K. Dhir, "Numerical Simulation of Saturated Film Boiling on a Horizontal Surface," Journal of Heat Transfer, vol. 119, no. 3, pp. 525-533, 1997. 
[4] S. W. J. Welch and J. Wilson, "A Volume of Fluid Based Method for Fluid Flows with Phase Change," Journal of Computational Physics, vol. 160, no. 2, pp. 662-682, 2000.

[5] G. Son and V. K. Dhir, "Three-dimensional simulation of saturated film boiling on a horizontal cylinder," International Journal of Heat and Mass Transfer, vol. 51, no. 5, pp. 1156-1167, 2008.

[6] V. K. Dhir and G. P. Purohit, "Subcooled film-boiling heat transfer from spheres," Nuclear Engineering and Design, vol. 47, no. 1, pp. 49-66, 1978.

[7] M. H. Yuan, Y. H. Yang, T. S. Li, and Z. H. Hu, "Numerical simulation of film boiling on a sphere with a volume of fluid interface tracking method," International Journal of Heat and Mass Transfer, vol. 51, no. 7, pp. 1646-1657, 2008.

[8] K. Kobayasi, "Film Boiling Heat Transfer around a Sphere in Forced Convection," Journal of Nuclear Science and Technology, vol. 2, no. 2, pp. 62-67, 1965.

[9] V. V. Yagov, A. R. Zabirov, and M. A. Lexin, "Unsteady heat transfer during subcooled film boiling," Thermal Engineering, Journal Article vol. 62, no. 11, pp. 833-842, 2015.

[10] N. Kosseifi, E. Hachem, L. Silva, S. A. E. Boyer, E. Massoni, and T. Coupez, "Numerical simulation of boiling during the quenching process," presented at the 10e colloque national en calculdes structures, Giens, France, May 2011

[11] R. E. Rosensweig, Ferrohydrodynamics. London: Cambridge University Press, 1985.

[12] R. Hiergeist et al., "Application of magnetite ferrofluids for hyperthermia," Journal of Magnetism and Magnetic Materials, vol. 201, no. 1, pp. 420-422, 1999.

[13] K. Nakatsuka, B. Jeyadevan, S. Neveu, and H. Koganezawa, "The magnetic fluid for heat transfer applications," Journal of Magnetism and Magnetic Materials, vol. 252, pp. 360-362, 2002.

[14] S. Shuchi, K. Sakatani, and H. Yamaguchi, "An application of a binary mixture of magnetic fluid for heat transport devices," Journal of Magnetism and Magnetic Materials, vol. 289, pp. 257-259, 2005.

[15] H. S. Park, D. Shiferaw, B. R. Sehgal, D. K. Kim, and M. Muhammed, "Film Boiling Heat Transfer on a High Temperature Sphere in Nanofluid," no. 46938, pp. 469-476, 2004.

[16] T. Arai and M. Furuya, "Effect of Nanofluid on the Film Boiling Behavior at Vapor Film Collapse,” no. 43536, pp. 633-638, 2009. 
[17] H. Kim, G. DeWitt, T. McKrell, J. Buongiorno, and L.-w. Hu, "On the quenching of steel and zircaloy spheres in water-based nanofluids with alumina, silica and diamond nanoparticles," International Journal of Multiphase Flow, vol. 35, no. 5, pp. 427-438, 2009.

[18] A. Bolukbasi and D. Ciloglu, "Pool boiling heat transfer characteristics of vertical cylinder quenched by $\mathrm{SiO} 2-$ water nanofluids," International Journal of Thermal Sciences, vol. 50, no. 6, pp. 1013-1021, 2011.

[19] D. Ciloglu and A. Bolukbasi, "The quenching behavior of aqueous nanofluids around rods with high temperature," Nuclear Engineering and Design, vol. 241, no. 7, pp. 2519-2527, 2011.

[20] J.-Q. Li, L.-W. Fan, L. Zhang, and Z.-T. Yu, "An Experimental Study of Boiling Heat Transfer During Quenching of Nanofluids With Carbon Nanotubes of Various Sizes," no. 50336, p. V002T08A002, 2016.

[21] A. Malvandi, S. Heysiattalab, and D. D. Ganji, "Thermophoresis and Brownian motion effects on heat transfer enhancement at film boiling of nanofluids over a vertical cylinder," Journal of Molecular Liquids, vol. 216, pp. 503-509, 2016.

[22] I. Nkurikiyimfura, Y. Wang, and Z. Pan, "Heat transfer enhancement by magnetic nanofluids-A review," Renewable and Sustainable Energy Reviews, vol. 21, pp. 548-561, 2013.

[23] H. Habibi Khoshmehr, A. Saboonchi, M. B. Shafii, and N. Jahani, "The study of magnetic field implementation on cylinder quenched in boiling ferro-fluid," Applied Thermal Engineering, vol. 64, no. 1, pp. 331-338, 2014.

[24] A. Malvandi, "Film boiling of magnetic nanofluids (MNFs) over a vertical plate in presence of a uniform variable-directional magnetic field," Journal of Magnetism and Magnetic Materials, vol. 406, pp. 95-102, 2016.

[25] A. Malvandi, "Anisotropic behavior of magnetic nanofluids (MNFs) at film boiling over a vertical cylinder in the presence of a uniform variable-directional magnetic field," Powder Technology, vol. 294, pp. 307-314, 2016.

[26] E. E. Tzirtzilakis and N. G. Kafoussias, "Three-Dimensional Magnetic Fluid Boundary Layer Flow Over a Linearly Stretching Sheet," Journal of Heat Transfer, vol. 132, no. 1, pp. 011702-011702-8, 2009.

[27] H. Yamaguchi, Engineering Fluid Mechanics. Netherlands: Springer Science, 2008.

[28] C. Kittel, Introduction to Solid State Physics. New York John Wiley \& Sons, 1967. 
[29] K. H. J. Buschow, Handbook of Magnetic Materials (no. v. 15). Elsevier Science, 2003.

[30] R. L. Hamilton and O. K. Crosser, "Thermal Conductivity of Heterogeneous Two-Component Systems," Industrial \& Engineering Chemistry Fundamentals, vol. 1, no. 3, pp. 187-191, 1962.

[31] K. Khanafer, K. Vafai, and M. Lightstone, "Buoyancy-driven heat transfer enhancement in a two-dimensional enclosure utilizing nanofluids," International Journal of Heat and Mass Transfer, vol. 46, no. 19, pp. 3639-3653, 2003.

[32] P. J. Berenson, "Film-Boiling Heat Transfer From a Horizontal Surface," Journal of Heat Transfer, vol. 83, no. 3, pp. 351-356, 1961.

[33] V. V. Klimenko, "Film boiling on a horizontal plate - new correlation," International Journal of Heat and Mass Transfer, vol. 24, no. 1, pp. 69-79, 1981.

[34] G. Son and V. K. Dhir, "Numerical Simulation of Film Boiling Near Critical Pressures With a Level Set Method," Journal of Heat Transfer, vol. 120, no. 1, pp. 183-192, 1998.

\section{Biographies}

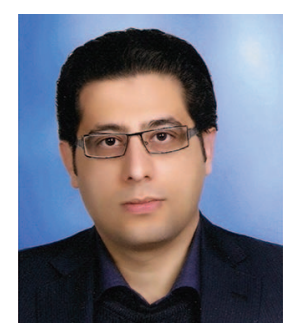

Rasool Maroofiazar received his B.Sc., M.Sc. and Ph.D. degrees in Mechanical Engineering from University of Tabriz, Iran. Dr. Maroofiazar is currently an Assistant Professor at the Department of Mechanical Engineering at the University of Maragheh, Iran. His research interests include Energy Harvesting, Nanofluid Flow and Heat Transfer, Two-phase Flows, and NonTraditional Machining.

Seyyede Fatemeh Haghgoo received her B.Sc. and M.Sc. degree in mechanical engineering from university of Tabriz, Iran. She is currently a Ph.D. student at Shahid Beheshti university. Her research focuses on Thermal Power Plants, Two-phase flows and PCM. 